\title{
In Vitro Anticoccidial Activity of Olive Pulp (Olea europaea L. var. Chemlal) Extract Against Eimeria Oocysts in Broiler Chickens
}

\author{
Nedjima Debbou-louknane ${ }^{1} \cdot$ Cristina Nerín $^{2} \cdot$ Meriem Amrane $^{3} \cdot$ Menana Ghemghar $^{3} \cdot$ Khodir Madani $^{3}$. \\ Abdelhanine Ayad ${ }^{1}$
}

Received: 11 April 2019 / Accepted: 23 August 2019 / Published online: 6 September 2019

(c) Witold Stefański Institute of Parasitology, Polish Academy of Sciences 2019

\begin{abstract}
Aim The objective of the present study was to investigate in vitro anticoccidial effect of olive pulp (Olea europaea $L$ var. Chemlal) extract on the destruction of Eimeria spp. oocysts isolated from infected chickens naturally.

Materials and methods The olive pulp (OP) powder was stirred manually in aqueous ethanol in preparation for extraction using the microwave-assisted extraction system. The identification of the phenolic compounds was obtained by ultra-highperformance liquid chromatography-mass spectrometry with electrospray ionisation (HPLC-ESI-MS). The treatment of Eimeria oocyst with OP extract and standard compounds (quercetin and oleuropein) leads to their lysis as shown by the release of substances absorbing at $273 \mathrm{~nm}$.

Results Our results showed that the maximum number of reduced oocysts was recorded after $8 \mathrm{~h}$ of incubation of optimum OP extract, quercetin and oleuropein for different periods of time. Also, the number of Eimeria oocysts decreased considerably with increase concentrations after adding the optimum of OP extract in concentration ranging from 0.023 to $0.371 \mathrm{mg} /$ $\mathrm{ml}$. Positive correlation between the optimum OP extract concentrations and the number of Eimeria oocysts reduced was $R^{2}=0.959$. From this in vitro experiment, it can be concluded that the OP extract possesses an anti-Eimeria spp activity. Conclusion To our knowledge, this is the first time that quercetin and oleuropein were tested to evaluate their anticoccidial activity. The findings of this study showed that phenolic compound of OP extract tested separately possesses anti-Eimeria spp. effect. Further studies should be carried out to test its in vivo efficacy of the OP bioactive compounds in broiler chickens.
\end{abstract}

Keywords Olea europea L. var. Chemlal · Co-products $\cdot$ Anticoccidial activity $\cdot$ Chickens $\cdot$ In vitro

\section{Introduction}

Coccidiosis is one of the most important diseases of poultry worldwide caused by protozoan parasites of the genus Eimeria. This infection causes an extensive destruction of the enterocytes [1] which results in reduced feed efficiency,

Abdelhanine Ayad

hanine06@gamil.com

1 Department of Environment Biological Sciences, Faculty of Nature and Life Sciences, University of Bejaia, Route de Targa Ouzemmour, 06000 Bejaïa, Algeria

2 Aragón Institute for Engineering Research (I3A), University of Zaragoza, Campus, Rio Ebro María de Luna 350018 Saragossa, Spain

3 Laboratory of Biomathematics, Biochemistry, Biophysics and Scientometrics (L3BS), University of Bejaia, Route de Targa Ouzemmour, 06000 Bejaïa, Algeria body weight gain, and a temporary reduction in egg production [2]. The worldwide annual losses due to Eimeria infection were estimated to more than $\$ 3$ billion [3].

It is very necessary to intensify control, especially in the current intensive farming conditions; because Eimeria oocysts are ubiquitous, easily disseminated in the broilers houses and their large reproduction potential [4]. Several factors can facilitate the disease development such as Eimeria virulence, high oocyst challenge, poor ventilation, high stocking density, low immune status of the host, bacterial enteritis, high humidity in litter and a lack of effectiveness of anticoccidial drugs. [5].

Since 60 years, anticoccidial drugs in feed of chickens have been used to control the coccidiosis [5, 6]. However, the main problem associated with their ineffective response is the development of resistance in Eimeria species of all synthetic available molecules [7-9]. In addition, 
the anticoccidial drugs in broiler meat may be potentially harmful to both the consumers and the environment $[10,11]$.

This situation encourages the use of herbal remedies in poultry diets instead of synthetic drugs. Some herbal extracts stimulate the immune system, enhance growth performance and can supply as well the anticoccidial effects [7]. Many studies have been carried out on medicinal plants and forages as alternative strategies to controlling avian coccidiosis and improving poultry performance worldwide [12, 13]. In Algeria, the olive trees represent a significant portion of the agricultural economy $(32,300,000$ trees) with production of $6,844,606$ quintals of olive oil as the production is variable from 1 year to another [14]. According to the Provincial Direction of Agricultural Services, a large part of the olive production is concentrated in Bejaia province $(600,551$ quintals, 5,212,000 olive trees) which generated a huge quantity of residues called pomace. Pomace is a very promising source of valuable substances, as they contain a large number of bioactive compounds $[15,16]$. These co-products become more and more usable in different fields, as animal feed, energy source and vegetation fertiliser [17-20]. However, to our knowledge, the anticoccidial activity of pomace olive has never been reported. The objective of the present study was to investigate in vitro anticoccidial effect of olive pulp (OP) extract on the destruction of Eimeria oocysts isolated from naturally infected chickens.

\section{Materials and Methods}

\section{Plant Materials}

The olive pulp (Olea europaea L., var. Chemlal) was collected in the traditional mill immediately after the olive pressing operation in the area of Bejaia (Algeria). Samples were dried for 17 days in the shade at room temperature until constant weight was obtained, and then crushed using a traditional grinder. The resulting powder was passed through a standard $250 \mu \mathrm{m}$ sieve. Only the fraction with particle size $\leq 250 \mu \mathrm{m}$ was collected, stored at $+4^{\circ} \mathrm{C}$ in amber bottles and sterilised until used.

\section{Extraction and Optimization of Total Phenolic Compounds (TPC)}

\section{Microwave-Assisted Extraction (MAE)}

A domestic microwave oven $(2450 \mathrm{MHz}$, Samsung Model NN-S674MF, Kuala Lumpur, Malaysia) was modified to extract the phenolic compounds from the olive pulp powder [21]. One gram of olive pulp powder was stirred manually in aqueous ethanol in preparation for extraction using the MAE system. The MAE parameters were microwave power
(300-700 W), extraction time (30-120 s), liquid-solid ratio $(10-50 \mathrm{ml} / \mathrm{g})$ and ethanol proportion $(20-50 \%)$. After that, the extract was filtered through a Buchner funnel lined with Whatman No 3 filter paper and the supernatant was collected in a volumetric flask. The extract was stored at $+4{ }^{\circ} \mathrm{C}$ until used.

\section{Determination of Total Phenolic Content}

The content of the total phenolics of the OP extract was determined according to the Folin-Ciocalteu test [22]. The absorbance of the extract was compared to a calibration curve of gallic acid to estimate the concentration of total phenolic (TPC) in the sample. PTC was expressed as mg Gallic Acid Equivalents (GAE) per gram of powder on a dry weight (DW) basis.

\section{Determination of Flavonoids Contents}

Aluminium chloride colorimetric method was used for flavonoids determination [23]. Briefly, $1 \mathrm{ml}$ of hydroethanolic extract solution was added to $1 \mathrm{ml}$ of $2 \%$ methanolic $\mathrm{AlCl}_{3-} 6 \mathrm{H}_{2} \mathrm{O}$ solution. The absorbance was measured with a spectrophotometer (UV-Vis SpectroScan 50) at $415 \mathrm{~nm}$ length wave after $10 \mathrm{~min}$ of equilibrium and then compared to a quercetin standard curve for the determination of the concentration of total flavonoids in the samples. The results were expressed in $\mathrm{mg}$ Quercetin/g Equivalent/g of powder on dry weight basis (mg QE/g DW).

\section{Determination of Condensed Tannin (Proanthocyanidins) Contents}

The method based on butanol/ $\mathrm{HCl}$ dosage was performed with small modifications [24]. Two hundred and fifty microliters of extract were mixed with $2.5 \mathrm{ml}$ of an acid solution of ferrous sulphate $(77 \mathrm{mg}$ of ferric ammonium sulphate $\left(\mathrm{Fe}_{2}(\mathrm{SO} 4)_{3}\right)$ dissolved in $500 \mathrm{~mL}$ of $(3: 2 n$-butanol: $\mathrm{HCl})$ ). After mixing and incubating at $95^{\circ} \mathrm{C}$ for $50 \mathrm{~min}$, the absorbance at $550 \mathrm{~nm}$ length wave was measured against a blank. Condensed tannins content (CTC) was calculated using the following formula:

$\mathrm{CTC}=\frac{A_{550 \mathrm{~nm}} \times \mathrm{DF} \times \mathrm{MW}}{\varepsilon L}$,

where DF is the dilution factor; MW is the molecular weight of the cyanidin $(287 \mathrm{~g} / \mathrm{mol}), \varepsilon$ is the molecular extinction coefficient $(34,700 \mathrm{l} / \mathrm{mol} / \mathrm{cm})$ and $L$ is the spectrophotometer cell thickness $(1 \mathrm{~cm})$. The condensed tannin concentrations $(\mathrm{mg} / \mathrm{ml})$ were expressed as $\mathrm{mg}$ of cyanidin $(\mathrm{CE})$ equivalents per $g$ of extract dry weight (DW). 


\section{Determination of the Antioxidant Activity}

\section{Scavenging Activity Against the ABTS ${ }^{+}$Radical}

The method of Re et al. [25] was adopted for the evaluation of the antioxidant activity of pulp olive extract. Briefly, a radical solution (7-mM ABTS and 2.45-mM potassium persulfate) was prepared in an ethanolic solution and left to stand in the dark at room temperature $\left(27^{\circ} \mathrm{C}\right)$ for $12-16 \mathrm{~h}$ before performing in the assay. This solution was then diluted with ethanol to get an absorbance of $0.700 \pm 0.02$ and equilibrated at $30^{\circ} \mathrm{C}$. The antioxidant activity (AOX) was calculated as the percentage of inhibition of absorbance at $734 \mathrm{~nm}$ length wave and the $\mathrm{IC}_{50}(\mu \mathrm{g} / \mathrm{ml})$ was determined as follows.

$\mathrm{AOX} \%=\left(A_{\text {control }}-A_{\text {sample }} / A_{\text {control }}\right) \times 100$,

where $A_{\text {control }}$ is the absorbance of the blank control (ABTS ${ }^{+}$. solution without test sample) and $A_{\text {sample }}$ is the absorbance of the test sample.

\section{Scavenging Activity Against the DPPH Radical}

The OP extract was tested for the scavenging effect on the DPPH' (1,1-diphényl-2-picryl-hydrazyl) radical using a colorimetric method [26]. $50 \mu \mathrm{l}$ of hydroethanolic extract at different concentrations was added to $2 \mathrm{ml}$ of DPPH stock solution $(0.004 \% ; \mathrm{w} / \mathrm{v})$ and the reaction mixture was thoroughly mixed and incubated for $30 \mathrm{~min}$ at $37^{\circ} \mathrm{C}$. The absorbance of the resulting solution was measured at $517 \mathrm{~nm}$ length wave with a spectrophotometer. As a positive control, a synthetic gallic acid antioxidant was used and the $\mathrm{IC}_{50}$ was determined. The DPPH radical scavenging activity $(S \%)$ was calculated using the following formula

$S \%=100 \times A_{\text {control }}-A_{\text {sample }} / A_{\text {control }}$,

where $A_{\text {control }}$ is the absorbance of the blank control (containing all reagents except the extract solution) and $A_{\text {sample }}$ is the absorbance of the sample.

\section{Measurement of the Ferric Reducing Power (FRAP)}

The ferric reducing power was determined as described by Oyaizu [27]. Briefly, $120 \mu \mathrm{l}$ of OP extract solution at different concentrations was mixed with $2.5 \mathrm{ml}$ of phosphate buffer (0.2 M, pH 7.4) and $2.5 \mathrm{ml}$ of potassium ferricyanide $(1 \%)$. After an incubation of the mixture at $50{ }^{\circ} \mathrm{C}$ for $20 \mathrm{~min}, 2.5 \mathrm{ml}$ of trichloroacetic acid (10\%; w/v) was added, and the mixture was centrifuged at $3000 \mathrm{rpm}$ for $10 \mathrm{~min}$. A $2.5-\mathrm{ml}$ aliquot of the supernatant was mixed with $2.5 \mathrm{ml}$ of distilled water and $0.5 \mathrm{ml}$ of ferric chloride $(0.1 \%$; w/v); then, the absorbance was measured at $700 \mathrm{~nm}$ wave length. The higher the absorbance value, the stronger the reducing power.

\section{High-Performance Liquid Chromatography-Mass Spectrometry (HPLC-ESI-MS) Analysis of Phenolic Compounds}

The identification of phenolic compounds of OP extract was obtained by ultra-high-performance liquid chromatography-mass spectrometry with electrospray ionisation (UPLC-ESI-MS) and quadrupole-time of flight detector (QTOF). The equipment was Xevo G2 mass spectrometer consisting of a hexapole, a collision cell and a time of flight analyser (QTOF) supplied by Waters (Milford, MA, USA). The electrospray probe was used in positive (ESI+) and negative (ESI-) modes as well as sensitivity analyser mode. The mass range considered was from 10 to $1000 \mathrm{Da}$. The corona voltage was $2.5 \mathrm{kV}$ for (ESI+) and $0.5 \mathrm{kV}$ for (ESI-). The sampling cone voltage was optimised between 20 and $50 \mathrm{~V}$. Finally, $30 \mathrm{~V}$ was selected for the screening because more peaks were detected. Other MS parameters were as follows: the source temperature was $150^{\circ} \mathrm{C}$, the desolvation gas temperature $450{ }^{\circ} \mathrm{C}$ and the desolvation gas flow $650 \mathrm{l} / \mathrm{h}$. MSE mode was selected for the acquisition, and collision ramp energy from 5 to $40 \mathrm{~V}$ was used. Mass Lynx v.4.1 software (Waters, Milford MA, USA) was used to analyse the samples and Croma Lynx (Waters, Milford MA, USA) was used to deconvolve the spectra. Quantitative data for pulp phenolic compounds were obtained by calibration curves obtained from known standards.

\section{Determination of the Anticoccidial Activity}

\section{Eimeria Oocysts Isolation and Purification}

Oocysts sample of Eimeria spp. was isolated from fresh faeces of broilers suffering from coccidiosis in Bejaia area (Algeria). The oocysts were sporulated by incubation in $2.5 \% \mathrm{~K}_{2} \mathrm{Cr}_{2} \mathrm{O}_{7}$ solution in the presence of suitable humidity and temperature [28]. Sporulated oocysts were washed and counted using Malassez chamber. Mean number of oocysts per millilitre of sample was calculated. The identification of Eimeria species in chickens was made on the basis of some standard parasitological techniques [28]. The oocysts were identified according to size, shape, presence or absence of micropyle, time of sporulation, intestinal location and appearance and coarse characteristics of intestinal lesions. The percentage of each species in the mixed suspension was approximately $32.05 \%$ E. acervulina, $26.92 \%$ E. tenella, $15.35 \%$ E. mitis, $14.10 \%$ E. brunetti and $11.53 \%$ E. maxima. 
The purification of the oocysts was carried out from onelitre phosphate-buffered saline (PBS, containing $8 \mathrm{~g} / \mathrm{l} \mathrm{NaCl}$, $0.2 \mathrm{~g} / \mathrm{KCl}, 1.13 \mathrm{~g} / 1 \mathrm{Na}_{2} \mathrm{HPO}_{4}, 2 \mathrm{H}_{2} \mathrm{O}$ and $0.2 \mathrm{~g} / 1 \mathrm{KH}_{2} \mathrm{PO}_{4}$ ) with some modifications [29]. Neutral substrates containing antibiotics (Streptomycin $1 \mathrm{mg} / \mathrm{ml}$ and penicillin V $100 \mathrm{IU}$ ) were added to prevent any bacterial evolution and Fluconazole $(17 \mathrm{mg} / \mathrm{ml})$ was added as antifungal agent. The $\mathrm{pH}$ was adjusted to 7.4 and the solution was sterilised by membrane filtration through a $0.2-\mu \mathrm{m}$ filter. The HBSS (Hanks' Balanced Salt Solution) medium was prepared in the laboratory (NaCI, 8.0; $\mathrm{KCl} 0,4 ; \mathrm{CaCl}_{2}, 0.139 ; \mathrm{D}$-glugose, 1.0; $\mathrm{Na}_{2} \mathrm{HPO}_{4}, 0,0478 ; \mathrm{KH}_{2} \mathrm{PO}_{4}, 0.06$ and $\mathrm{MgSO}_{4}, 0.097 \mathrm{~g} / \mathrm{l}$ in 11 of distilled water). The solution was sterilised as well as that of the $0.2 \%$ agar.

\section{Effects of the Pulp Extract and Standard Compounds on the Decrease of Oocysts Number}

The activity of olive pulp extract and standard compounds (quercetin and oleuropein) (Fisher scientific, Fair Lawn, NJ, USA) was determined in triplicate by incubation at ambient temperature for $24 \mathrm{~h} \mathrm{[30].} \mathrm{The} \mathrm{suspension} \mathrm{solution} \mathrm{was} \mathrm{incu-}$ bated at different periods of time: $0,1,2,4,6,8$ and $24 \mathrm{~h}$. One millilitre suspension contains: $100 \mu \mathrm{l}$ of washed suspension of Eimeria oocysts at $4.16 \times 10^{6}$ oocysts $/ \mathrm{ml} ; 700 \mu \mathrm{l}$ of PBS; $200 \mu \mathrm{l}$ of the optimum olive pulp extract. After incubation, the samples were centrifuged at $320 \mathrm{~g}$ for $5 \mathrm{~min}$ and the absorbance of the supernatant was measured at $273 \mathrm{~nm}$ by spectrophotometer (Shimadzu, model: UV 100 Japan). Then, the percentage of destruction of sporulated oocysts was estimated. The $\mathrm{LC}_{50}$ value was then inferred from the regression curve. The number of oocysts was counted three times in a cell volume of $1 \mu \mathrm{l}$ amounts to $4.16 \times 10^{4}$. The ethanol solvent was also used as a negative control.

\section{Effect of the Diclazuril, Sulfaquinoxaline Sodium on the Decrease of the Oocysts Number}

Diclazuril (Diclosol ${ }^{\circledR}$, Avico, Arab Industry Veterinary Co, Amman, Jordanie) and Sulfaquinoxaline sodium (Coccidiopan $^{\circledR}$, Avico, Arab Industry Veterinary Co, Amman, Jordanie) were tested in triplicate $(0.1,0.3,0.5$, 0.7 and $1 \mathrm{mg} / \mathrm{ml}$ ) using the microplate method described by Remmal et al. [31]. The number of oocysts was counted twice in a cell volume of $1 \mu \mathrm{l}$ amounts to $2.32 \times 10^{4}$.

\section{Statistical Analysis}

A statistical analysis was performed using $\mathrm{JMP}^{\circledR}$ Software, version 7.0 (SAS Institute Inc, 2007). The results were expressed in mean \pm SE. The values were statistically significant when the $P$ value was $\leq 0.05$. Inoculums suspension taken on time $0,1,2,4,6,8$ and 24 h on oocysts number was examined by the Student's $t$ test. The lethal concentration is defined as the concentration that reduces the initial number of sporulated oocysts to $50 \%$.

\section{Results}

The optimum of OP (Olea europaea L., var. Chemlal) concentration $(22.30 \mathrm{mg} / \mathrm{g} ; 0.743 \mathrm{mg} / \mathrm{ml}$ and $03 \mathrm{~min})$ and the optimised parameters of the extract of OP are illustrated in Fig. 1. The identification of the phenolic compounds of the OP extract by ultra-high-performance liquid chromatography-mass spectrometry with electrospray ionisation (HPLC-ESI-MS) revealed the presence of biophenol molecules (Fig. 2). The quantitative data for the phenolic compounds of the extract were obtained by calibration curves from known standards.

The antioxidant capacities of the OP extract at different dilutions $(1 / 2,1 / 4,1 / 8,1 / 16,1 / 32,1 / 64$ and 1/128) and the standard compounds (quercetin, oleuropein) at different concentrations $(0.05,0.1,0.3,0.5,0.7$ and $1 \mathrm{mg} / \mathrm{ml})$ were evaluated by DPPH, ABTS $^{+\bullet}$ and FRAP tests (Table 1$)$. The $\mathrm{IC}_{50}$ determination shows a significant difference $(P<0.05)$ between the OP extract and the used standards. Quercetin has a pronounced antioxidant activity $(0.102 \pm 0.014 \mathrm{mg} / \mathrm{ml})$ compared to oleuropein and OP extract $(0.276 \pm 0.037$ and $0.509 \pm 0.047 \mathrm{mg} / \mathrm{ml}$, respectively).

According to our results, the OP extract and the standards compound tested at different concentrations $(0.743$ and $0.139 \mathrm{mg} / \mathrm{ml}$, respectively) showed that the number of oocysts decreases after the treatment. However, the quercetin was most effective (45.38\%), followed by oleuropein and the OP extracts (33.25\% and $25.36 \%$ ), respectively, after 8 -h treatment. The lethal concentration $\mathrm{LC}_{50}$ of $\mathrm{OP}$ extract and diclazuril were $14.44 \pm 1.206$ and $0.5 \pm 7711$ $\mathrm{mg} / \mathrm{ml}$, respectively. The ethanol-treated Eimeria suspension (negative control) was significantly $(P \leq 0.05)$ higher than the tested concentration of OP extract and the standards compound. The result of two anticoccidial effects (diclazuril and sulfaquinoxaline sodium) on the number of oocysts at $0.5 \mathrm{mg} / \mathrm{ml}$ concentration is shown in Fig. 5 .

Figure $3 \mathrm{a}-\mathrm{c}$ showed that a rate of $25.36,45.38$ and $33.25 \%$ of the oocysts number reduced has been recorded after $8 \mathrm{~h}$ of incubation with $0.745 \mathrm{mg} / \mathrm{ml}$ of the optimum OP extract, quercetin and oleuropein for different periods of time, respectively. This decrease in the number of oocysts causes a considerable release of $273 \mathrm{~nm}$ absorbing material from Eimeria oocysts that this depends on the concentration of the optimum OP extract, quercetin and oleuropein.

Figure 4 shows the number of Eimeria oocysts decreases considerably with increase in concent rations of OP extract in concentration ranging from 0.023 to $0.371 \mathrm{mg} /$ $\mathrm{ml}$. Positive correlation between the optimum OP extract 
Fig. 1 Optimization of parameters of extraction of olive pulp (Olea europaea L., var. Chemlal) by microwave
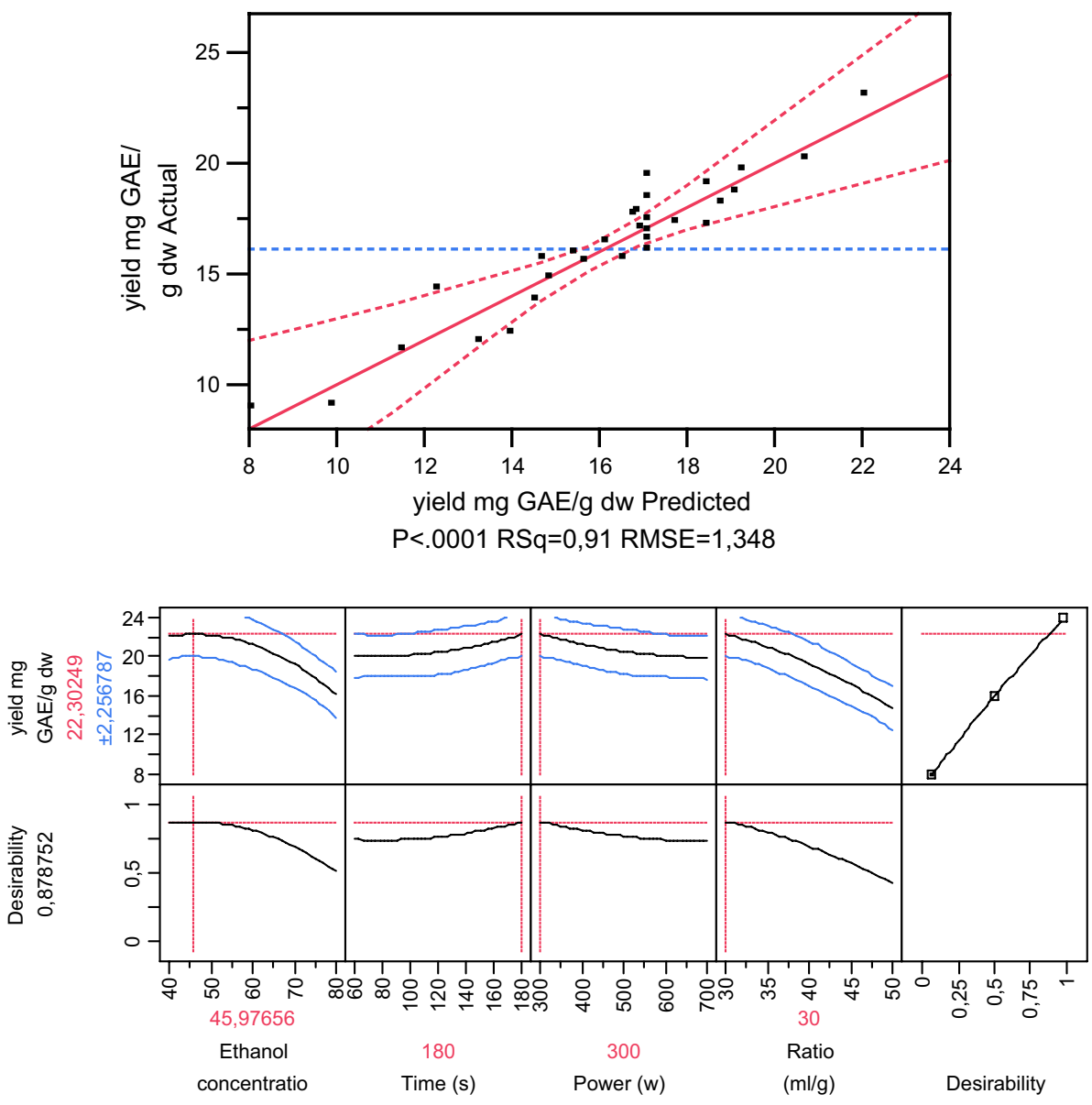

concentrations and the number of Eimeria oocysts reduced was $R^{2}=0.959$. The result of two anticoccidial effects (diclazuril and sulfaquinoxaline sodium) on the number of oocysts at $0.5 \mathrm{mg} / \mathrm{mL}$ concentration is shown in Fig. 5 .

\section{Discussion}

The use of plant extracts as remedy can attenuate the resistance of coccidia to medications and their impact on consumer's health, because they are not only natural products, but also include new therapeutic molecules for which no resistance has never been reported [32, 33]. This work was carried out to find a phytotherapic substance to help the control of Eimeria parasites in broiler chicken and to provide an alternative use of a plant extracts. To our knowledge, this is the first study to evaluate the effect of anticoccidial of the OP optimum (Olea europaea L., var. Chemlal) extract and their phenolic compounds directly on the viability of Eimeria oocysts collected from broiler chicken parasites in vitro. The results of this investigation have demonstrated that the OP extracts have a noticeably destructive effect on Eimeria parasite. Previous investigations have used in vitro test to screen the anticoccidial effect of some plant compounds in broiler chickens [34-38].

The study carried out by Hady and Zaki [12] demonstrated that Artemisia annua extract decreases the bloody diarrhoea in broilers experimentally infected by E. tenella compared to the infected control group. Other researchers reported that Artemisia annua and Foeniculum vulgare have an anticoccidial activity in chickens infected by E. tenella, and a significant reduction in faecal oocysts was recorded [39]. Likewise, Artemisia herba-alba anticoccidial activity was relied on decreasing excretion of E. tenella oocyst and bloody diarrhoea as reported by Messai et al. [40].

As described before in several studies, the phenolic components (flavonoids, flavonoids, phenolic acid, tannins, etc.) revealed a wide range of biological properties such as antibacterial, antiviral, anticancer, anti-proliferative and anti-inflammatory [41-45]. These compounds or secondary metabolites particularly possess also anti-protozoan activities, especially against Plasmodium, Leishmania and Trypanosoma spp. [46-50]. Then, the phenolic compounds are good candidate molecules due to a relatively low or no toxicity and because the presence of some flavonoids limits the resistance of protozoan to other drugs [51]. Moreover, the polyphenols from Palmae (Cocos nucifera L.) fibres 


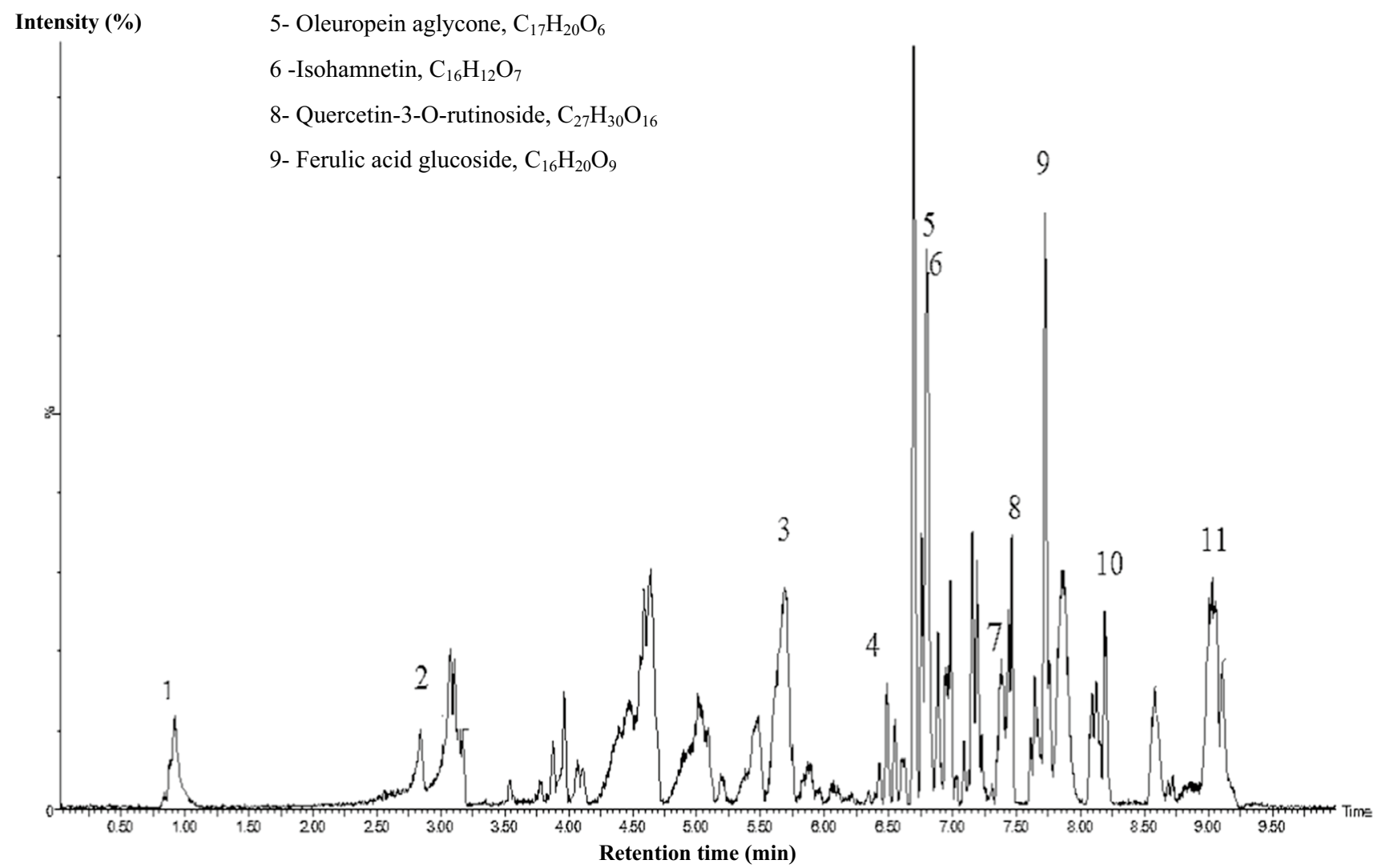

Fig. 2 HPLC-ESI-MS chromatograms of the phenolic profile of the olive pulp extract (Olea europaea L., var. Chemlal)

Table 1 DPPH, $\mathrm{ABTS}^{+\bullet}$ and FRAP tests of phenolic compounds of the olive pulp extract (Olea europaea L., var. Chemlal), quercetin and oleuropein

\begin{tabular}{|c|c|c|c|c|c|}
\hline \multirow[t]{2}{*}{ Compounds } & \multicolumn{2}{|c|}{$\begin{array}{l}\mathrm{IC}_{50} \text { Concentration }(\mathrm{mg} / \\
\mathrm{ml}, \pm \mathrm{SD})\end{array}$} & \multicolumn{2}{|c|}{ Inhibition (\%) } & \multirow{2}{*}{$\begin{array}{l}\text { FRAP } \\
\text { (OD, } \\
1 \mathrm{mg} / \\
\mathrm{ml} \text { ) }\end{array}$} \\
\hline & DPPH & ABTS & DPPH & ABTS & \\
\hline Quercetin & $0.10 \pm 0.01$ & $0.12 \pm 0.03$ & 76.52 & 65.64 & 2.08 \\
\hline Oleuropein & $0.23 \pm 0.01$ & $0.28 \pm 0.0$ & 59.2 & 58.72 & 1.18 \\
\hline $\begin{array}{l}\text { Hydroetha- } \\
\text { nolic extract } \\
\text { of pulp }\end{array}$ & $0.51 \pm 0.05$ & $0.54 \pm 0.05$ & 25.36 & 23.54 & 1.76 \\
\hline
\end{tabular}

$I C_{50}$ inhibitory concentration $50, S D$ standard deviation, $O D$ optical density, $D P P H$ 1,1-diphényl-2-picryl-hydrazyl, ABTS 2,2'-azino-bis (3-éthylbenzothiazoline-6-sulphonique

showed antiproliferative activity against Leishmania amazonensis [52].

In the present study, the OP extract used as natural anticoccidial product is very interesting because the results of the characterization by HPLC show that the OP extract contains large concentrations of polyphenolic compounds or biophenoles (Caffeoylputrescine, apigenin 7-O-glucoside, oleuropein aglycone, quercetin 3,7,-O-glucoside, 3,4-DHPEA-EA,
quercetin-3-O-rutinoside, diligustilide, ferulic acid glucoside, 4- $p$-coumaroylquinic acid, deacetoxyoleuropein aglycon). In addition, the major compounds of OP extract are flavonoids called again bioflavonoid. It should be noted that these flavonoids are recognised archetypal antioxidants such as oleuropein (OE), hydroxytyrosol (HT), tyrosol (T), coumaric acid, ferulic acid, caffeic acid, quercetin, etc. and had interesting biological activities [53]. In addition, Ghanbari et al. [54] confirmed that the different parts of olives and their by-products have a valuable bioactive profile as well as medicinal and functional proprieties.

The OP extract at different concentrations showed a significant antioxidant activity in agreement with those reported by Morelló et al. [55] and Moudache et al. [56, 57]. The results of present study correspond also with those published previously, which demonstrated that the antioxidant activity of plant extracts contains quercetin and oleuropein [58-63]. Antioxidant activity is often accompanied by antiviral and antibacterial activities of the phenolics compounds. In addition, it was shown that the antioxidant activity of flavonoids is determined by the presence of free hydroxyl groups and their mutual location [64].

The results of DPPH, $\mathrm{ABTS}^{+\bullet}$ and FRAP tests of the optimum and the standard compounds (quercetin, 

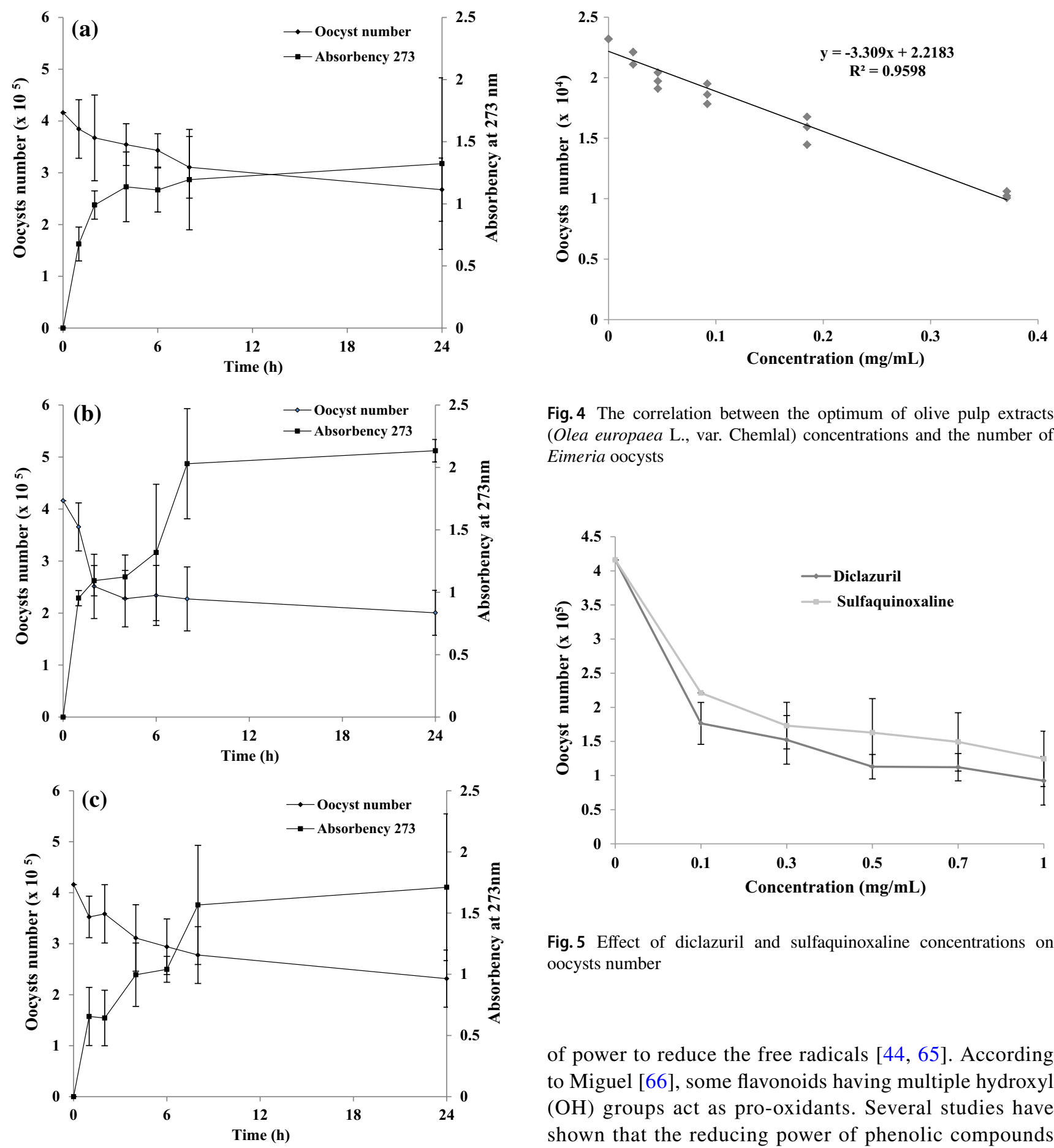

Fig. 4 The correlation between the optimum of olive pulp extracts (Olea europaea L., var. Chemlal) concentrations and the number of Eimeria oocysts

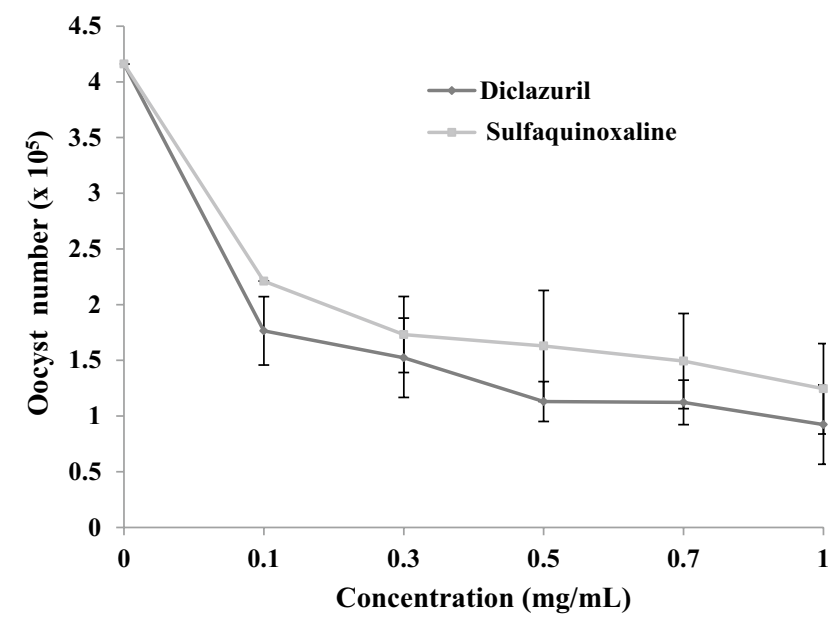

Fig. 5 Effect of diclazuril and sulfaquinoxaline concentrations on oocysts number

Fig. 3 Kinetics of the decrease of the oocysts number and $273 \mathrm{~nm}$ wave length absorbing material release from Eimeria oocysts treated by optimum of olive pulp extract (Olea europaea L., var. Chemlal) (a), quercetin (b) and oleuropein (c)

oleuropein) were revealed by the antioxidant capacities. However, the difference of quercetin, oleuropein and the optimum of OP extract values could be attributed to a polar character which can contribute to the potentialisation

of power to reduce the free radicals $[44,65]$. According to Miguel [66], some flavonoids having multiple hydroxyl $(\mathrm{OH})$ groups act as pro-oxidants. Several studies have shown that the reducing power of phenolic compounds can be considered as an indicator potential antioxidant effect $[67,68]$. The results of this study correspond also with those published previously, which demonstrated the antioxidant activity of the olive oil co-product [69]. This effect could due attributed to the hydrogen donor ability to form stable free radicals, thus preventing the oxidation and their propagation. In addition, the mixtures of different phenolic compounds present in the olive oil co-product extracts have greater antioxidant activity than the individual compounds because of their synergy [70]. 
To test the decrease potential of the OP extract on Eimeria parasite in broiler chicken, the extract optimal concentration $(22.3024 \mathrm{mg} / \mathrm{g}$ GAE of dry matter: $0.743 \mathrm{mg} / \mathrm{ml})$ was used to define the time necessary for the oocysts maximum reduction. The results of anticoccidial effect have been evaluated from the lysed oocysts number after treatment depending on time. This observation is based on the alteration state of oocysts treated surfaces and the cells fragmentation. Note that the positive control is also taken into account which gives a strong support for the tested extract. The data of this study showed a correlation of OP extract concentrations with the reduced oocysts numbers. This destructive effect of oocysts is a result of intracellular content release such as aromatic amino acids and nucleotides that are expressed by UV absorption substances after treatment [31]. The results of this study also correspond to those previously published, which showed that the increase in the concentration of plant extracts leads to an increase in anticoccidial activity [30,31]. Regarding the concentration of extraction solvent at $45.97 \%$ ethanol (Fig. 1) of optimum extract, neither destruction of oocysts nor deleterious effect were recorded. In contrast, Gadelhaq et al. [71] reported that a significant effect of inhibition of sporulation and oocysts deterioration occurred at high ethanolic concentrations (50 and 70\%).

This anticoccidial activity could be attributed to an individual or a combined effect of the bioactive compounds [72]. These constituents could play many beneficial-associated properties such as antioxidant and anti-inflammatory effects associated with compounds rich in bioactive elements (e.g., polyphenolic) $[73,74]$. Our in vitro results could be explained by the in vivo positive effects of the olive pulp extract on the chicken production reported by Sayehban et al. [20]. The results of this study correspond to those previously published, which demonstrated that the anticoccidial activity might be due to the bioactivity constituents such as ascorbic acid, flavonoids, phenol compounds and carotenoids [75, 76].

Many investigations have established relationships between the activity, the chemical structure and the mode of action of flavonoids as well as the absorption level and their bioavailability [5, 77-79]. In this research, it may be assumed that the different proportions of OP extract, quercetin and oleuropein are related to factors cited previously. In addition, the hydrophilic and hydrophobic nature of bioactive (quercetin and oleuropein, respectively) may be the major cause of anticoccidial activity. According to Tasdemir et al. [80], quercetin showed an in vitro leishmanicidal activity with IC 50 of $1.0 \mu \mathrm{g} / \mathrm{ml}$. The insertion of two $\mathrm{OH}$ functions improved considerably the leishmanicidal in vivo activity with $15.3 \%$ of inhibiting infection, while other flavonoids were completely inactive.

It has been demonstrated that the olive pulp of the family Oleaceae has higher antioxidant activity, mainly residing in the hydrophilic nature [55], in contrary to oleuropein. This could be explained by the fact that oleuropein is to some extent polar and thus, it would rapidly diffuse through the bilayer of the intestinal epithelial cell membrane [81]. On the other hand, Gourama and Bullerman [82] showed that oleuropein has an influence on the development and sporulation of Aspergillus parasiticus. It is important to underline that those natural antioxidants containing soluble lipid seem to be more effective due to their penetration into the cell, which could affect the intracellular of Eimeria [83].

In the present investigation, the difference in proportions (oocysts destroyed) could be explained by the difference of polarity and the hydrophilic or lipophilic nature. Also, other studies showed the beneficial effect of plant extracts against multiple or monospecific infections with either E. tenella or E. acervulina [84, 85]. This is supported by Allen and Danforth [86], who demonstrated that the antioxidant compounds are well known to have a cellular protective action against oxidative stress and reduce the severity of E. tenella infections by altering the degree of intestinal lipid.

According to Peek and Landman [87], the use of Diclazuril $(0.5 \mathrm{mg} / \mathrm{ml})$ showed a significant reductive efficiency on sporulated Eimeria oocysts after 24 h of incubation compared to our results, while the sulfaquinoxaline showed a slight reduced oocysts number. Indeed, in agreement with our observations, many investigations demonstrated that the in vitro anticoccidial effect of diclazuril is high [88, 89]. This difference may be attributed necessarily to pharmacological properties of drugs and their action on coccidia development. Diclazuril lethal effect against both asexual and sexual stages of E. tenella, E. necatrix and E. acervulina, the gametocytes of $E$. brunetti, and the zygote of $E$. maxima was documented [90].

\section{Conclusion}

From this in vitro experiment, it can be concluded that the OP (Olea europaea L., var. Chemlal) extract possesses the ability to destroy Eimeria spp. collected from naturally infected broiler chickens. To our knowledge, this is the first time that quercetin and oleuropein are tested to evaluate their anticoccidial activity. The findings of this study showed that phenolic compound of OP extract tested separately possesses anti-Eimeria effect. Further studies should be carried out to test the in vivo efficiency of the OP bioactive compounds in broiler chickens.

Author contributions NID carried out the experimental work and wrote the manuscript. CN participated in biochemistry analysis of extract plant and reviewed the manuscript. MA, MG and KM contributed in technical assistance of plant extraction. AA designed, supervised the 
experimental study and reviewed the manuscript. All authors read and approved the final manuscript.

\section{Compliance with ethical standards}

Conflict of interest The authors declare that they have no potential conflict of interest.

Ethical approval Ethics committee approval was received for this study from the scientific committee of Faculty of Life and Nature Sciences, University A. Mira, Bejaia, Algeria.

\section{References}

1. Lillehoj HS, Okamura M (2003) Host immunity and vaccine development to coccidia and Salmonella infections in chickens. Poultry Sci 40:151-193

2. Razzaq A, Ali T, Saghir A, Arshad S, Cheema A (2011) Training needs assessment of poultry farmers in tehsil Faisalabad. J Anim Plant Sci 21:629-631

3. Dalloul RA, Lillehoj HS (2006) Poultry coccidiosis: recent advancements in control measures and vaccine development. Expert Rev Vaccines 5:143-163

4. Allen PC, Fetterer RH (2002) Recent advances in biology and immunobiology of Eimeria species and in diagnosis and control of infection with these coccidian parasites of poultry. Clin Mic Rev 15:58-65

5. Shivaramaiah C, Barta JR, Hernandez-Velasco X, Téllez G, Hargis BM (2014) Coccidiosis: recent advancements in the immunobiology of Eimeria species, preventive measures, and the importance of vaccination as a control tool against these Apicomplexan parasites. Vet Med Res Reports 5:23-34

6. Blake DP, Tomley FM (2014) Securing poultry production from the ever-present Eimeria challenge. Trends Parasitol 30:12-19

7. Abbas RZ, Iqba Z, Khan MN, Zafar MA, Zia MA (2010) Anticoccidial activity of Curcumalonga L. in broiler chickens. Braz Arch Biotech 53:63-67

8. Abbas RZ, Iqbal Z, Blake D, Khan MN, Saleemi MK (2011) Anticoccidial drug resistance in fowl coccidia: the state of play revisited. World's Poultry Sci J 67:337-350

9. Alnassan AA, Thabet A, Daugschies A, Bangoura B (2015) InVitro efficacy of allicin on chicken Eimeria tenella sporozoites. Parasitol Res 114:625-630

10. Ogbe AO, Mgbojikwe LO, Abdu PA, Atawodi SE (2008) Organ and carcass weight variation and histopathological changes in Eimeria tenella infected broiler chickens treated with aqueous extract of a wild mushroom (Ganoderma lucidum). Electron J Env Agri Food Chem 7:2906-2913

11. Nogueira VA, França TN, Peixoto PV (2009) Ionophore poisoningin animals. Pesq Vet Bras 29:191-197

12. Hady NMM, Zaki MM (2012) Efficacy of some herbal feed additives on performance and control of cecal coccidiosis in broilers. APCBEE Procedia 4:163-168

13. Masood S, Abbas RZ, Iqbal Z, Mansoor MK, Sindhu ZUD, Zia MA, Khan JA (2013) Role of natural antioxidants for the control of coccidiosis in poultry. Pak Vet J 33(4):401-407

14. Ministry of Agriculture and Rural Development (MARD), Algeria. Le renouveau agricole et rural en marche. Revue et perspectives. Published 15 July 2018. http://www.minagri.dz please mention here the exact URL, this link took me to the ministry website

15. Vega-Galvez A, Miranda M, Punte Diaz L, Lopez L, Uribe E, Rodriguez K (2010) Effective moisture diffusivity determination and mathematical modeling of the drying curves of the olivewaste cake. Bioresour Technol 101:7265-7270

16. Yu J, Zhang J, He J, Liu Z, Yu Z (2009) Combinations of mild physical or chemical pretreatment with biological pretreatment for enzymatic hydrolysis of rice hull. Bioresour Technol 100:903-908

17. Christian MS, Sharper VA, Hoberman AM, Seng JE, Fu L, Covell D, Diener RM, Bitler CM, Crea R (2004) The toxicity profile of hydrolyzed aqueous olive pulp extract. Drug Chem Toxicol 27:309-330

18. De Pablos LM, Santos MFBD, Montero E, Garcia-Granados A, Parra A, Osuna A (2010) Anticoccidial activity of maslinic acid against infection with Eimeria tenella in chickens. Parasitol Res 107:601-604

19. Gacioui F, Hadj Amar Z, Oussaid S (2013) Extraction, optimisation et pouvoir antioxydant des polyphenols des feuilles d'oleastre. Nut Santé 2:30-38

20. Sayehban P, Seidavi A, Dadashbeiki M, Ghorbani A, Araujo WAG, Albino LFT (2016) Effects of different levels of two types of olive pulp with or without exogenous enzyme supplementation on broiler performance and economic parameters. Braz J Poultry Sci 18:489-500

21. Dahmoune F, Nayak B, Moussi K, Remini H, Madani K (2014) Optimization of microwave-assisted extraction of polyphenols from Myrtus communis L. leaves. Food Chem 166:585-595

22. Georgé S, Brat P, Alter P, Amiot MJ (2005) Rapid determination of polyphenols and vitamin C in plant-derived products. J Agric Food Chem 53:1370-1373

23. Quettier-Deleu C, Gressier B, Vasseur J, DineT Brunet C, Luyckx M et al (2000) Phenolic compounds and antioxidant activities of buckwheat (Fagopyrum esculentum Moench) hulls and flour. J Ethnopharmacol 72:35-42

24. Vermerris W, Nicholson R (2006) The role of phenols in plant defence. In: Vermerris W, Nicholson R (eds) Phenolic compound biochemistry, Chapter 6. Springer, Dordrecht, pp 211-234

25. Re R, Pellegrini N, Proteggente A, Pannala A, Yang M, RiceEvans C (1999) Antioxidant activity applying an improved ABTS radical cation decolorization assay. Free Radic Biol Med 26:1231-1237

26. Brand Williams W, Cuvelier ME, Berset C (1995) Use of free radical method to evaluate antioxidant activity. LWT Food Sci Technol 28:25-30

27. Oyaizu M (1986) Studies on products of browning reactions: antioxidative activities of product of browning reaction prepared from glucosamine. Jpn J Nut 44:307-315

28. Carvalho FS, Wenceslau AA, Teixeira M, Alexandre J, Carencro M, Diego A, Milo AD, George B, Albuquerque R (2011) Diagnosis of Eimeria species using traditional and molecular methods in field studies. Vet Parasitol 176:95-100

29. Rhayour K, Bouchikhi T, Tantaoui-Elaraki A, Sendide K, Remmal A (2003) The mechanism of bacterial action of oregano and clove essential oils and of their phenolic major components on Escherichiacoli and Bacillussubtillis. J Essent Oil Res 15:286-292

30. Remmal A, Achahbar S, Bouddine L, Chami F, Chami N (2013) Oocysticidal effect of essential oil components against chicken Eimeria oocysts. Int J Vet Med 2013:599816

31. Remmal A, Achahbar S, Bouddine L, Chami N, Chami F (2011) In-Vitro destruction of Eimeria oocysts by essential oils. Vet Parasitol 182:121-126

32. Becerril R, Nerín C, Gómez-Lus R (2012) Evaluation of bacterial resistance to essential oils and antibiotics after exposure to oregano and cinnamon essential oils. Foodborne Pathog Dis 9(8):699-705

33. Ola-Fadunsin SD, Ademola IO (2014) Anticoccidial effects of Morindalucida acetone ex tracts on broiler chickens naturally infected with Eimeria species. Phar Biol 52:330-334 
34. Molan AL, Zhuojian L, De S (2009) Effect of pine bark (Pinus radiata) extracts on sporulation of coccidian oocysts. Folia Parasitol 56:1-5

35. Narsih KS, Wignyanto WS (2012) Identification of aloin and saponin and chemical composition of volatile constituents from Aloe vera (L.) Peel. J Agric Food Tech 2:79-84

36. Pieri FA, Silva VO, Vargas FS, Veiga Junior VF, Moreira MAS (2014) Antimicrobial activity of Copaiferalangsdorffii oil and evaluation of its most bioactive fraction against bacteria of dog's dental plaque. Pak Vet J 34:165-169

37. Xiao CW, Ji QA, Rajput ZI, Wei Q, Liu Y, Bao GL (2014) Antifungal efficacy of Phellodendronamurense ethanol extract against Trichophyton mentagrophytes in rabbits. Pak Vet $\mathbf{J}$ $34: 219-223$

38. Habibi H, Firouzi S, Nili H, Razavi M, Asadi SL, Daneshi S (2016) Anticoccidial effects of herbal extracts on Eimeria tenella infection in broiler chickens: in-vitro and in-vivo study. J Parasit Dis 40:401-407

39. Drãnga L, Györke A, Ferreira JFS, Pop IA, Dunca I, Drăgan M, Mircean V, Dan I, Cozma V (2014) Effects of Artemisia annua and Foeniculum vulgare on chickens highly infected with Eimeria tenella (Phylum Apicomplexa). Acta Vet Scand 56:22

40. Messai A, Bensegueni A, Abdeldjelil M, Agabou A, RedouaneSalah S (2014) Effects of white wormwood (Artemisia herba-alba Asso) during an experimental coccidiosis in broilers. Ann Biol Res 5:61-66

41. Yao LH, Jiang YM, Shi J, Tomas-barberán FA, Datta N, Sinsaganusong R, Chen SS (2004) Flavonoids in food and their health Benefits. Plant Foods Human Nut 59:113-122

42. Ghedira K (2005) Les flavonoïdes: structure, propriétés biologiques, rôle prophylactique et emplois en thérapeutique. Phytothérapie 4:162-169

43. Ghedadba N, Hambaba L, Ayachi A, Aberkane MC, Bousselsela H, Oueld Moukhtar SM (2015) Polyphénols totaux, activités antioxydante et antimicrobienne des feuilles de Marrubium deserti de Noé. Phytothérapie 13:118-129

44. Liu Y, Young K, Rakotondraibe LH, Brodie PJ, Wilev JD, Cassera MB, Callmander MW, Rakotondrajaona R, Rakotobe E, Rasamisson VE, Tendvke K, Shen Yand Kingston DG (2015) Antiproliferative compounds from cleistanthus boivinianus from the Madagascar dry forest. J Nat Prod 78:1543-1547

45. Dai Y, Liu Y, Rakotondraible LH (2018) Novel bioactive natural products isolated from madagascar plants and marine organisms (2009-2017). Chem Pharm Bull 66:469-482

46. Kayser O, Albrecht FK, Simon LC (2003) Natural products as potential antiparasitic drugs. Parasitol Res 90(2):S55-S62

47. Nikmehr B, Ghaznavi H, Rahbar A, Sadr S, Mehrzadi S (2014) In-Vitro anti-leishmanial activity of methanolic extracts of Calendula officinalis flowers, Datura stramonium seeds, and Salvia officinalis leaves. Chinese J Nat Med 12:423-427

48. Sülsen VP, Puente V, Papademetrio D, Batlle A, Martino VS, Frank FM, Lombardo ME (2016) Mode of action of the sesquiterpene lactones psilostachyin and psilostachyin C on Trypanosoma cruzi. PLoS One 11:e0150526

49. Ramdane F, Essid R, Fares N, El Ouassis D, Aziz S, Mahammed MH, Ould Hadj MD, Limam F (2017) Antioxidant antileishmanial cytotoxic and antimicrobial activities of a local plant Myrtus nivellei from Algeria Sahara. Asian Pac J Trop Biomed 7:702-707

50. Panda KS, Luyten W (2018) Antiparasitic activity in Asteraceae with special attention to ethnobotanical use by the tribes of Odisha, India. Parasite 25:10

51. Kerboeuf D, Riou M, Guégnard F (2008) Flavonoids and related compounds in parasitic disease control. Mini Rev Med Chem $8: 116-128$

52. Mendonça-Filho RR, Rodriguez IA, Alviano DS, Santos AL, Soares RM, Alviano CS, Lopes AH, Rosa Mdo S (2004)
Leishmanicidal activity of polyphenolic-rich extract from husk fiber of Cocos nucifera Linn. (Palmae). Res Microbiol 155:136-143

53. Dabrosca D, Pacifico S, Cefarelli G, Mastellone C, Fiorentino A (2007) Limoncella apple, an Italian apple cultivar: phenolic and flavonoid contents and antioxidant activity. Food Chem 104:1333-1337

54. Ghanbari R, Anwar F, Alkharfy KM, Gilani AH, Saari N (2012) Valuable nutrients and functional bioactives in different parts of olive (Olea europaea L.) - a review. Int J Mol Sci 13(3):3291-3340

55. Morelló JR, Vuorela S, Rome MP, Motilva MJ, Heinonen M (2005) Antioxidant activity of olive pulp and olive oil phenolic compounds of the Arbequina cultivar. J Agric Food Chem 53:2002-2008

56. Moudache M, Colon M, Nerín C, Zaidi F (2016) Phenolic content and antioxidant activity of olive by-products and antioxidant film containing olive leaf extract. Food Chem 212:521-527

57. Moudache M, Nerín C, Colón M, Zaidi F (2017) Antioxidant effect of an innovative active plastic film containing olive leaves extract on fresh pork meat and its evaluation by Raman spectroscopy. Food Chem 229:98-103

58. Somova LI, Shode FO, Ramnanan P, Nadar A (2003) Antihypertensive, antiatherosclerotic and antioxidant activity of triterpenoids isolated from Olea europaea, subspecies africana leaves. J Ethnopharmacol 84:299-305

59. Skerget M, Kotnik P, Hadolin M, Hras AR, SimonicM Knez Z (2005) Phenols, proanthocyanidins, flavones and flavonols in some plant materials and their antioxidant activities. Food Chem 89:191-198

60. Bougatef A, Hajji M, Balti R, Lassoued L, Triki-Ellouz Y, Nasri M (2009) Antioxidant and free radical-scavenging activities of smooth hound (Mustelus mustelus) muscle protein hydrolysates obtained by gastrointestinal proteases. Food Chem 114:1198-1205

61. Tamatopoulos S, Katsoyannos E, Chatzilazarou A (2014) Antioxidant activity and thermal stability of oleuropein and related phenolic compounds of olive leaf extract after separation and concentrations by salting- out- assisted cloud point extraction. Antioxidants 3:229-244

62. Yua JJ, Wang CZ, Ye JZ, Tao R, Zhang YS (2015) Enzymatic hydrolysis of oleuropein from Olea europea (Olive) leaf extract and antioxidant activities. Molecules 20:2903-2921

63. Cordero JG, GarcíaRE, Avila J, Gargini R, Escudero VG (2018) Beneit of oleuropein aglycone for Alzheimer's disease by promoting autophagy. Oxid Med Cell longev 2018:5010741

64. Wang L, Tu YCh, Lian TW, Hung JT, Yen JH, Wu J (2006) Distinctive antioxidant and antiinflammatory effects of flavonols. J Agric Food Chem 54:9798-9804

65. Lafka TI, Lazou Andriana E, Sinanoglou Vassilia J, Lazos Evangelos S (2013) Phenolic extracts from wild olive leaves and their potential as edible oils antioxidants. Food 2:18-31

66. Miguel MG (2010) Antioxidant activity of medicinal and aromatic plants. A review. Flavour Fragr J 25:291-312

67. Kumaran A, Karunakaran RJ (2007) In-vitro antioxidant activities of methanol extracts of five Phyllanthus species from India. LWT Food Sci Technol 40:344-352

68. Bougandoura N, Bendimered N (2012) Evaluation de l'activité antioxydante des extraits aqueux et méthaloniques de Satureja calamintha spp. Nepeta (L.) Briq. Nat Techn 9:14-19

69. Xie P, Huang L, Zhang C, Zhang Y (2015) Phenolic compositions, and antioxidant performance of olive leaf and fruit (Olea europaea L.) extracts and their structure activity relationships. J Funct Foods 16:460-471

70. Ramos P, Santos S, Guerra Ă, Guerreiro O, Felício L, Jerónimo E, Silvestre A, Pascoal C, Duarte M (2013) Valorization of olive mill residues: antioxidant and breast cancer anti-proliferative activities 
of hydroxytyrosol-rich extracts derived from olive oil by-products. Ind Crops Prod 46:359-368

71. Gadelhaq SM, Arafab WM, Abolhadid SM (2018) In-Vitro activity of natural and chemical products on sporulation of Eimeria species oocysts of chickens. Vet Parasitol 251:12-16

72. Kalmobé J, Ndjonka D, Boursou D, Vildina JD, Liebau E (2017) Phytochemical analysis and in-vitro anthelmintic activity of Lophira lanceolata (Ochnaceae) on the bovine parasite Onchocerca ochengi and on drug resistant strains of the free-living nematode Caenorhabditis elegans. BMC Complement Altern Med 17:404

73. Fadili K, Amalich S, Ndedianhoua SK, Bouachrine M, Mahjoubi M, El Hilali F, Zair T (2015) Polyphenols content and antioxidant activity of two species from Moroccan High Atlas: rosmarinus officinalis and Thymus satureioides. Int J Innovation Sci Res 17:24-33

74. Kandouli C, Cassien M, Mercie A, Delhedde C, Ricquerbourg E, Stocker P, Mekaouche M, Leulmi Z, Mechakra A, ThétiotLaurent S, Culcasi M, Pietri S (2017) Antidiabetic, antioxidant and anti-inflammatory properties of water and n-butanol soluble extracts from Saharian Anvillea radiate in high-fat-diet fed mice. J Ethnopharmacol 207:251-267

75. Fard MT, Arulselvan P, Karthivashan G, Adam SK, Fakurazi S (2015) Bioactiveextract from Moringa oleifera inhibits the proinflammatory mediators in lipopolysaccharide stimulated macrophages. Pham Mag 11:556-563

76. Abdel-Latif M, El- Shahawi G, Aboelhadid SM, Abdel-Tawab $\mathrm{H}$ (2017) Modulation of murine intestinal immunity by Moringa oleifera extract in experimental hymenolepiasis nana. J Helminthol 6:1-12

77. Manso S, Cacho-Nerin F, Becerril R, Nerín C (2013) Combined analytical and microbiological tools to study the effect on Aspergillus flavus of cinnamon essential oil contained in food packaging. Food Control 30(2):370-378

78. Clemente I, Aznar M, Silva F, Nerín C (2016) Antimicrobial properties and mode of action of mustard and cinnamon essential oils and their combination against foodborne bacteria. Innov Food Sci Emerg Technol 36:26-33

79. Clemente I, Aznar M, Salafranca J, Nerín C (2017) Raman spectroscopy, electronic microscopy and SPME-GC-MS to elucidate the mode of action of a new antimicrobial food packaging material. Anal Bioanal Chem 409(4):1037-1048

80. Tasdemir D, Kaiser M, Brun R, Yardley V, Schmidt TJ, Tosun F, Rüedi P (2006) Antileishmanial activities of flavonoids and their analogues: in-vitro, in-vivo, structure-activity relationship, and quantitative structure-activity relationship studies. Antimicrob Agents Chemother 50:13

81. EdgecombeSC StretchGL, Hayball PJ (2000) Oleuropein, an antioxidant polyphenol from olive oil, is poorly absorbed from isolated perfused rat intestine. J Nut 130:2996-3002

82. Gourama H, Bullerman LB (1987) Effects of oleuropein on growth and aflatoxin production by Aspergillus parasiticus. Unknown $\mathrm{J}$ 20:226-228

83. Atawodi SE, Liman ML, Onyike EO (2013) Antioxidant effects of Tamarindus indica following acute and chronic carbon tetrachloride induced liver injury. Int J Agric Bio 15:410-418

84. Kurkure NV, Kolte SW, Bhandarkar AG, Kalorey DR (2006) Evaluation of herbal coccidiostat "coxynil" in broilers. Ind J Exp Biol 44:740-744

85. Chandrakesan P, Muralidharan K, Kumar VD, Ponnudurai G, Harikrishnan TJ, Rani KSVN (2009) Efficacy of a herbal complex against caecal coccidiosis in broiler chickens. Vet Arh 79:199-203

86. Allen PC, Danforth HD (1998) Effects of dietary supplementation with n-3 fatty acid esters on coccidiosis in chickens. Poultry Sci 77:1631-1635

87. Peek H, Landman, WJM (2011) Coccidiosis in poultry: anticoccidial products, vaccines and other prevention strategies. Vet $\mathrm{Q}$ 31(3):143-161

88. El-Banna HA, El-Bahy MM, El-Zorba HY, El-Hady M (2005) Anticoccidial efficacy of drinking water soluble diclazuril on experimental and field coccidiosis in broiler chickens. J Vet Med A 52:287-291

89. Ruiz A, Guedes AC, Muñoz MC, Molina JM, Hermosilla C, Martín S, Hernández YI, Hernández A, Pérez D, Matos L, López AM, Taubert A (2012) Control strategies using diclazuril against coccidiosis in goat kids. Parasitol Res 110(6):2131-2136

90. Conway DP, McKenzie ME (2007) Poultry coccidiosis and effect of coccidiosis diagnostic and testing procedures, 3rd edn. Blackwell Publishing, Ames

Publisher's Note Springer Nature remains neutral with regard to jurisdictional claims in published maps and institutional affiliations. 